\title{
sciendo
}

\section{PERSPECTIVES OF NATIONAL COORDINATORS FOR ANIMAL GENETIC RESOURCES ON THE EUROPEAN REGIONAL FOCAL POINT: SURVEY RESULTS*}

\author{
Elzbieta Martyniuk $^{1 *}$, Vera Matlova ${ }^{2}$, Nina Sæther ${ }^{3}$, Danijela Bojkovski ${ }^{4}$, Lorraine Puzin ${ }^{5}$, \\ Grazyna Polak ${ }^{6}$, Sipke Joost Hiemstra ${ }^{7}$, Beate Berger ${ }^{8}$, Jeanne Bormann ${ }^{9}$, Eva-Marie Stålhammar ${ }^{10}$, \\ Srdjan Stojanović ${ }^{11}$, Jan Tomka ${ }^{12}$ \\ ${ }^{1}$ Institute of Animal Sciences, Warsaw University of Life Sciences, ul. Ciszewskiego 8, \\ 02-786, Warszawa, Poland \\ ${ }_{2}^{2}$ Institute for Animal Science, National Centre for Animal Genetic Resources, Prátelství 815 \\ 10400 Praha 10, Czech Republic \\ ${ }^{3}$ Norwegian Genetic Resource Centre, P.O. Box 115, N-1431 Ås, Norway \\ ${ }^{4}$ Department of Animal Science, Biotechnical Faculty, University of Ljubljana, \\ Groblje 3, 1230 Domzale, Slovenia \\ ${ }^{5}$ Ministry of Agriculture, Agrifood and Forestry, General Directorate for the Economic \\ and Environmental Performance of Enterprises, 3 rue Barbet de Jouy, 75349 Paris 07 SP, France \\ ${ }^{6}$ National Research Institute of Animal Production, 32-083 Balice n. Kraków, Poland \\ ${ }^{7}$ Centre for Genetic Resources, the Netherlands (CGN), Wageningen University \& Research P.O. Box \\ 338, NL-6700 AH Netherlands \\ ${ }^{8}$ Federal Ministry of Agriculture, Forestry, Environment and Water Management Institute for Organic \\ Agriculture and Biodiversity Austrasse 10, Postfach 1214601 Thalheim, Austria \\ ${ }^{9}$ Administration of Technical Agricultural Services Animal Production Service, 16, rte d'Esch, \\ L-1470 Luxembourg, Luxembourg \\ ${ }^{10}$ Swedish Board of Agriculture, Division for International Affairs and Contingency Planning, \\ Jordbruksverket, 55182 Jönköping, Sweden \\ ${ }^{11}$ Ministry of Agriculture, Forestry and Water Management, Division for Rural Development, \\ Nemanjina 22-26, 11000 Belgrade, Serbia \\ ${ }^{12}$ National Agricultural and Food Centre, Research Institute for Animal Production Nitra, Institute \\ for Animal Husbandry Systems, Breeding and Product Quality, Hlohovecká 2, \\ 95141 Luzianky, Slovakia \\ •Corresponding author: elzbieta_martyniuk@sggw.edu.pl
}

\begin{abstract}
The European Regional Focal Point for Animal Genetic Resources (ERFP), is the European regional platform of National Coordinators (NCs) supporting management of animal genetic resources (AnGR). To assess the performance of the ERFP platform/network and consider options for its further development, a survey was performed among NCs. Twenty-five NCs responded to the survey on the roles, values and future of the platform. The paper provides an analysis of the results of the survey, including a ERFP SWOT analysis. NCs indicated high value of the support
\end{abstract}

\footnotetext{
*Ad hoc Action of the European Regional Focal Point for Animal Genetic Resources.
} 
of the ERFP in fulfilling their functions at the national level. They highlighted the well-established network and facilitated communication and collaboration among NCs and other AnGR experts in Europe. The NCs appreciated the efficient organizational structure of the ERFP(Working Groups, Task Forces, Ad hoc Actions), and the well-functioning Secretariat. Indicated weak points included discontinuity of $\mathrm{NC}$ positions in some countries, and low levels of activities in some countries. NCs saw new opportunities for ERFP development in the context of the EU policy and regulatory framework related to AnGR management, and in strengthening the role of the Secretariat. No immediate threats were identified, however potential future threats included insufficient financing and lack of continuity. The NCs highly appreciated the substantial progress achieved by the ERFP over the last 20 years.

Key words: animal genetic resources, management, cooperation, Europe

The European Regional Focal Point for Animal Genetic Resources (ERFP, 2020) is the regional platform to support in situ and ex situ conservation and sustainable use of AnGR, and facilitates implementation of the FAO's Global Plan of Action for AnGR at national and regional levels (FAO, 2007).

With over 20 years of working together as European NCs for AnGR, it was time for reflection and evaluation of achievements, as well as opportunity to review and gather expectations regarding future collaboration. Experiences of the ERFP platform provide lessons to be shared with other regions. Therefore, the account of the ERFP development has been included to provide context for the analysis of the survey.

The FAO/UNEP1980 Technical Consultation on AnGR held in Rome was a major milestone (Kubbinga et al., 2007) that eventually led to establishment and adoption in 1993, of the FAO technical work programme named the Global Strategy for Management of Farm Animal Genetic Resources (FAO, 1999). Each FAO member nation was invited to nominate a NC to initiate actions on the conservation of endangered native breeds, to promote sustainable use initiatives and to communicate with FAO (Wagner and Hammond, 1999).

The first opportunity for European NCs to meet was at a workshop organized by Keith Hammond (FAO), taking advantage of the annual meeting of the European Association for Animal Production (EAAP, at present European Federation of Animal Science) in Prague, 1995. Since then, the European National Coordinators have met every year at the margin of the EAAP meetings. In 1998, thanks to the efforts of Dominique Planchenault, the NC from France, an informal European Regional Focal Point for AnGR was initiated (Martyniuk and Planchenault, 1998). The ERFP was formally established during a meeting held in Budapest, 2001, and was initially financed through voluntary contributions of a number of member countries. The first ERFP Secretariat was established in Paris in 2001, thanks to the generous support of the Government of France and promotion of this idea by Louis Olliver (INRA: the National Institute for Agricultural Research) and Jean Boyazoglou (FAO). The terms of reference of the ERFP (ToR) included a rolling Secretariat. France hosted the Secretariat for the first years, then the Secretariat functions were provided by the University of Thessaloniki, Greece (2007-2010), then by BLE - German Federal Office for Agriculture and Food (2011-2014), and then followed by the Department 
of Animal Science, University of Ljubljana, Slovenia (2015-2018). Since 2019, the ERFP Secretariat has been hosted again by France, within the French Livestock Institute (IDELE).

In 2010, the financing model of the ERFP was changed, and this model remains in place today. Rather than relying on a few donor countries, each country is assessed a voluntary participation fee based on the UN GDP formula. With this funding approach, the ERFP is able to generate adequate financial resources to support its yearly activities, which are decided upon during the General Assembly (GA) of NCs.

At the beginning, the ERFP activities focused on facilitation of communication and collaboration among NCs, as well as implementation of projects that were submitted through so called 'Calls for Action'. The projects had to be approved by the ERFP governing body - the Steering Committee (SC) elected by NCs during the GA, and needed to take into account geographical balance to ensure representation of all of Europe.

The next major reform came in 2011, when the mode of operation of the ERFP was changed. The implementation of projects, involving usually a limited number of countries, was replaced with establishment of more permanent structures, Working Groups (WG) and Task Forces (TF), and Ad hoc Actions, when needed. This permanent structure is dynamic in terms of time and participating countries. At present, three Working Groups are active: Ex situ conservation (cryo-conservation), Documentation and Information, and In situ conservation and valorisation of AnGR. The last has operated since 2018.

To implement specific tasks the ERFP has established, over time, five temporary Task Forces: Agri-environmental Measures; Risk Status and Indicators; Access and Benefit sharing; EU matters; and In situ conservation and valorisation of AnGR. The Access and Benefit Sharing Task Force was operated for the longest period, 20112019. The ERFP established a roster of experts in various technical and policy fields to be called upon as needed to address specific issues and implement relevant tasks.

Various activities can be enabled through the $A d$ hoc Actions proposed by NCs, and decided upon by the Steering Committee. Ad hoc Actions include projects or workshops, as well as meetings or consultations with the objective to solve/address specific short-term problems or issues. Since 2011, the ERFP has implemented many such initiatives, some of them periodically, such as preparation of the ERFP positions for regular sessions of the FAO Intergovernmental Technical Working Group on Animal Genetic Resources (ITWG-AnGR). The various bodies established by the ERFP are described at: https://www.animalgeneticresources.net/index.php/abouterfp/how-do-we-operate/.

In 2011, the ERFP adopted a Multi-Year Programme of Work (MYPOW), and since then developed internal policies and rules on many issues, for example: operational structures of the ERFP, annual GA meetings, the role of the Secretariat and the Steering Committee and travel reimbursement rules. The current structure and operation of the ERFP was established taking into account a number of objectives: to facilitate broad participation of NCs in the ERFP activities, to share experiences, to develop new ideas (e.g. EUGENA) and to avoid duplication of work (e.g. preparation for FAO meetings). 
Over time, the Steering Committee has been chaired by a number of colleagues: Mike Roper (UK, 2001-2008); Asko Mäki-Tanila (FI, 2008-2012); Catherine Marguerat-König (CH, 2012-2015); and since 2015, Sipke Joost Hiemstra (NL).

The study presented in the paper is based on views of National Coordinators appointed by their governments as expressed in a survey that was undertaken as an Ad hoc Action of the ERFP. The objective of the Ad hoc Action SWOT ERFP was to review the work of the network and analyse its strengths, weaknesses, future opportunities and potential threats. As suggested by Mäki-Tanila and Hiemstra (2010), when planning future strategies for AnGR conservation and use, it is useful to regularly conduct a SWOT analysis (strengths, weaknesses, opportunities and threats). Key outcomes of the survey were presented at the ERFP GA in August 2018. Taking into account the wealth of information and ideas provided during this process, the GA recommended preparation of a paper to facilitate sharing experiences of the ERFP with other regions. The paper provides an analysis of the results of the survey, including the SWOT analysis.

\section{Material and methods}

\section{The survey and its organization}

The NCs survey addressed the current strategy and operation of the ERFP, potential improvements and priorities, as well as strategic directions for the future work of the ERFP. In addition, the survey was meant to identify issues that require further discussion in the context of the preparation of a new MYPOW of the ERFP.

The process to carry out the $A d$ hoc Action involved development of a draft survey and consultations with the Members of the Ad hoc Action group and Steering Committee. The survey was launched by the Secretariat involving all European NCs in May, 2018. A reminder note was sent to NCs and there was follow-up with some NCs.

The survey included 28 questions divided into four parts: I. General information, II. ERFP evaluation: general issues, III. ERFP evaluation: support for the NCs, and IV. The SWOT analysis. The survey was carried out using an online questionnaire tool. Twenty-five NCs provided complete surveys. Of these, nineteen identified themselves, while six were anonymous. Detailed information on received responses to all questions is contained in the survey as provided in the report of the Ad hoc Action SWOT ERFP, presented during the GA in Zagreb, 2018 (Martyniuk, 2018).

\section{Results}

\section{Part I. Profile of Respondents and general issues (Questions 1-9)}

The majority of the respondents work for either the government $(45 \%)$ or are in the research sector (41\%). The remaining ones are affiliated with educational institutions or other organizations. The NC appointments change frequently, as $32 \%$ of 
NCs had been appointed since 2015 , and $40 \%$ since 2008 . Only one NC was nominated before 1997, and six between 1997 and 2008. Surprisingly, 40\% of the NCs had not been involved at all in the work of the National Focal Point on AnGR prior to their nomination, and $36 \%$ were involved only shortly before. Six respondents were fully prepared to take on the role of $\mathrm{NC}$ at the time of their appointment, having worked for a long period on AnGR issues.

Most of the respondents were actively involved in the ERFP activities. Many NCs were members of one or more different ERFP bodies. Six NCs had not been involved personally in any ERFP bodies, but had nominated national experts to participate in either WGs or Ad hoc Actions. In eight countries, no national experts were involved in ERFP activities.

Almost three-quarters ( $72 \%$ ) of NCs reported to be actively involved in the work and activities of the FAO, representing their countries at the FAO ITWG-AnGR meetings, and in some cases, meetings of the FAO Commission on Genetic Resources for Food and Agriculture (CGRFA). Only 36\% of NCs reported involvement in the intergovernmental work at the EU level. This minority is not surprising as involvement is relevant only for EU member states, and is more common for NCs working for their governments.

\section{Part II. ERFP overall evaluation (Questions 10-18)}

The general evaluation of the importance of the ERFP as a platform for NCs was considered as very positive, with $40 \%$ of respondents indicating that the ERFP is extremely important, and $40 \%$ as very important.

While all NCs considered current organizational structures generally useful and to be maintained, $32 \%$ of respondents had suggestions on further developments and improvements. These NCs stressed that enhancement of active participation of national experts and NCs in WGs, Task Forces and Ad hoc Actions is needed; that these bodies should have clear goals and be output oriented; that there is a need to further develop and implement the internal and external communication strategy and to employ an external communication expert, and that efforts to enhance tools that are already available and currently in use (e.g. website, social media, etc.) would be valuable. Views were also expressed that ERFP should consider more permanent establishment of the Secretariat.

Fourteen respondents were pleased with the current governance structure of the ERFP, while four had no views on current structure. Seven had specific proposals for change, indicating a need to enhance the role of the SC by promoting better communication to its members and the other NCs, particularly within the sub-regions that $\mathrm{SC}$ members represent. It was also suggested that the minutes and other outcomes of SC meetings should be communicated to all NCs. Some NCs felt that certain rules and procedures (e.g. travel reimbursement) should be less strict and formal, and that a bottom-up participatory approach regarding various ERFP activities should be further promoted.

In regard to the organisation and running of the General Assembly, 13 NCs had no specific proposals. The remaining 12 NCs put forward a long list of detailed issues, drawing attention to the need for more time for discussion at the GA, as well as 
moving from reporting on activities of ERFP bodies, to sharing national experiences and problems.

The current rotational system of the ERFP Secretariat was supported by $44 \%$ of the respondents, while objected to by $32 \%$. Some respondents $(24 \%)$ had no strong views on the rotational system. It was underlined that hosting of the Secretariat puts significant burden on the host country, and may not be the most efficient organizational structure. It was also noted that the current rotation system is vulnerable, dependent on the host country contributing to some of the operational expenses of the Secretariat. However, some respondents indicated that the current system may be cheaper than establishing a permanent Secretariat.

The current funding mechanism was considered as satisfactory by $52 \%$ of the respondents, however, $36 \%$ were not sure this is the case. Many respondents suggested that there is no better alternative. Some NCs indicated that ERFP should take a strict approach on country payments to avoid 'free riders'. At present, members of various ERFP bodies are entitled to receive travel reimbursement regardless of their country contributing the annual payment. A few NCs presented various internal obstacles making it difficult to pay ERFP country contribution. For such countries, the principle of solidarity is crucial in order to ensure participation in ERFP activities. Several NCs also suggested that the level and the range of national contribution needs revision; in-kind contributions and the funding through research projects should also be taken into consideration.

Forty-four percent of respondents had specific suggestions on how the ERFP structure/organisation or the role of ERFP should be developed over the next 10 years. It was suggested that ERFP should not only serve as a network or communication platform, but it should be more visible and communicate with 'sister organisations' and to the outside world. ERFP may become more visible and act in a more official way as a reference centre/consulting body (e.g. EU Reference Centre for endangered breeds in the context of the EU animal breeding legislation). It was also underlined that more collaboration with other genetic resources networks e.g. ECPGR (The European Cooperative Programme for Plant Genetic Resources) for plants is needed, as generic issues could be dealt with across networks.

It was again pointed out that some further external professional and permanent support for the administrative and economic matters is needed on a structural basis, which may lead to future establishment of a permanent Secretariat. Some respondents expected more guidance and assistance to deal with key issues at the national level, such as Agri-Environmental schemes and development of gene banks, etc.

When respondents were asked to identify successful ERFP activities, 80\% mentioned two such activities while $64 \%$ identified three. The most common successful examples included: the organizational structure including WGs and TFs (12 respondents), the European Farm Animal Biodiversity Information System (EFABIS), the European Gene Bank Network EUGENA (6 each), networking within the ERFP framework, strong liaisons with FAO and its ITWG-AnGR (5 each), and back-toback meetings and workshops organized by the ERFP (4 NCs).

Twelve NCs were able to identify only one activity of the ERFP that they considered a failure or unnecessary, three NCs had two such examples, and only one 
provided three examples. The examples were diverse reflecting personal views with only three of them being shared by two respondents. Those included: the ERFP Newsletter and not achieving legal status for ERFP, as well as doubts if additional fields proposed in DAD-IS (FAO Domestic Animal Diversity Information System) and then reflected in EFABIS are needed and useful. Some comments indicated that there were no failures, however noting that some actions were not completed or sufficiently successful, such as motivating countries to actively participate in ERFP activities.

\section{Part III. ERFP evaluation - support for the NCs (Questions 19-24)}

In this part of the survey, respondents were invited to identify the most important areas in conservation and sustainable use of AnGR that require strengthening in their countries. Respondents were not limited on the number of suggested activities, and additional areas could be added to the provided list of potential activities contained in the questionnaire. Respondent replies are shown in Table 1.

Table 1. Percentage of respondents that identified predefined areas of activities in the management of AnGR that require strengthening at the national level

\begin{tabular}{l|c}
\hline \multicolumn{1}{c|}{ Areas of activities } & $\%$ \\
\hline $\begin{array}{l}\text { Ex situ conservation, including setting the legal framework and operational plan for } \\
\text { establishment of a national Gene Bank }\end{array}$ & 64 \\
Sustainable breeding programmes for endangered native breeds & 52 \\
Raising awareness in society and among consumers & 52 \\
In situ conservation & 48 \\
Valorisation of breed products and services & 44 \\
Inventory and monitoring of within breed diversity & 36 \\
Development of policies and legislation & 32 \\
Inventory and monitoring of between breed diversity & 24 \\
Knowledge transfer and capacity building & 24 \\
Cooperation with and between stakeholders & 4 \\
\hline
\end{tabular}

Table 2. Percentage of respondents that identified predefined areas of activities in the management of AnGR that should be enhanced at the national level through collaboration within the ERFP

\begin{tabular}{lc}
\multicolumn{1}{c}{ Areas of activities } & $\%$ \\
\hline Ex situ conservation & 68 \\
Valorisation of breed products and services & 52 \\
In situ conservation & 48 \\
Development of policies and legislation & 40 \\
Raise awareness in society and among consumers & 36 \\
Cooperation with and between stakeholders & 32 \\
Inventory and monitoring of between breed diversity & 28 \\
Inventory and monitoring of within breed diversity & 24 \\
\hline
\end{tabular}


For the majority of respondents, ex situ conservation was the most important area to pursue. Over half of the respondents underlined the need for establishment of sustainable breeding programmes and building awareness in society on the importance of the conservation of AnGR diversity. No additional areas were added by respondents to the predefined list.

The respondents also identified areas that would benefit from collaboration within the ERFP network (Table 2). The respondents could mark all the areas they considered relevant for collaboration as well as suggest other ones.

Ex situ conservation was indicated by the majority of respondents as the priority area of work that needed to be strengthened at the national level with expected support from the ERFP. Another important technical issue was valorisation of products and services that will help raise awareness of the importance of native endangered breeds and strengthen in situ activities at the national level. Some respondents indicated further development of tools to evaluate effectiveness of the breeding programmes.

The respondents noted that ERFP engagement at the international level (FAO/ EU) is supporting their work in the area of AnGR management at the national level. For $20 \%$ of NCs, this was extremely important, and very important for $40 \%$, None of the respondents indicated that this engagement is not relevant to their work.

Respondents were asked if ERFP has had an impact on recognition of their NC position at the national level. Only seven NCs stated that their involvement in the ERFP activities had enhanced recognition of their position. Thirteen NCs indicated that at present their participation in the ERFP has had limited role in enhancing support, four NCs indicated that their involvement was not relevant in gaining national level support. One NC did not answer this question.

Respondents were also invited to identify organizational and communicational elements of the current work of the ERFP that might be strengthened. In total, 42 examples were provided; 24 NCs provided at least one example, while 10 provided three or more. The most mentioned elements included: an improved ERFP Website (6 respondents); a regular newsletter that provided information on the latest developments in AnGR (4); enhanced exchange of information, using social media, web-discussions (video chat), use of video conferences etc. (4); better communication with policymakers and involvement in development of new policies and policy implementation (3); promoting success stories and developing examples on best practices, and providing annual country reports on the ERFP webpage (2).

Respondents provided 44 proposals on how the ERFP network could support their work in future. Common expectations included, firstly enhancement of tangible ERFP-generated outputs such as guidelines, reports, case studies with recommendations, statements on AnGR related issues, as well as tools, e.g. to evaluate effectiveness of breeding programmes (6). The second area indicated is requiring further ERFP support related to the international level. The NCs proposed that ERFP could serve as the communication platform to inform on developments at FAO and the EU levels by identifying, anticipating and contributing to discussions on major policy issues (e.g. engagement in the development of the next Common Agriculture Policy of the EU) (5). Also, five respondents would like the ERFP to strengthen 
the EUGENA network, develop a next version of CRYOweb, improve EFABIS, and provide options for uploading and downloading information (web services, CSV...). Some NCs would like to see ERFP involvement in applying for EU projects (e.g. Horizon, 2020), and to support collaborative research/management of shared transboundary breeds (4). Some noted that the ERFP support is needed in some countries in developing breeding and conservation programmes for AnGR, with ERFP experts providing arguments and examples on the importance of agrobiodiversity conservation and facilitated domestic developments.

\section{Part IV. SWOT analysis (Questions 25-28)}

The last part of the survey was a SWOT analysis. Respondents were asked to identify at least three elements they considered as strong points of the ERFP. In total, 25 respondents identified 59 examples, 14 NCs mentioned three or more examples, three NCs gave one example, and no examples were provided by two NCs.

Many respondents indicated that ERFP provides a good framework for networking and collaboration of all NCs and other AnGR experts in Europe. The network integrates and supports European NCs (EU and Non-EU) in their roles and in undertaking initiatives (e.g. EFABIS, EUGENA), which are useful for all countries (12). It was highlighted that ERFP is a forum for exchanging views and opinions on a number of matters (legislation, research and implementation); and provides a good platform to share best practices, exchange information, and share experiences and skills. It was noted that the network is open for participation for all countries, based on solidarity, with equal access to all activities and outputs (8) by all participating countries.

The current organizational structure (WGs, TFs and Ad hoc Actions), as well as a well-functioning Secretariat, open discussions and efficient decision-making at the annual GA and transparency of all ERFP activities, were noted as strengths by six NCs. It was also stressed that ERFP has established its position in international institutions (links with FAO, EAAP, EU) with resulting impacts on EU policy on the conservation of AnGR (3).

With respect to weak points of the ERFP, the NCs provided in total 51 examples. Eleven NCs were able to identify three or more examples, while six named only one. Many NCs indicated that the obstacles in ERFP's functionality are related to instability and discontinuity of the NCs in some member countries, and might be a reason that not all countries are sufficiently active. As a result, the main activities usually involve the same "strong group" of NCs that shape the ERFP strategy. Some countries have difficulties to find people ready to work in the ERFP WGs.

It was also mentioned that cooperation with some Eastern European countries is lacking (e.g. Russia) in spite of many efforts to involve them. The communication between the SC and the NCs could also be improved (12).

For some NCs, EFRP access to EU institutions and lobbying power is still not sufficient, and sometimes it is reflected at the national level with difficulty to finance annual contributions. Also, the presentation of the ERFP work to the general public is too weak, and there is generally lack of awareness on importance of AnGR management and the ERFP as an institution (5). 
Five NCs stated that the current financial mechanism based on the voluntary contributions is a weak point because the annual budget is difficult to predict and can limit the range of activities and number of participants at the ERFP events. However, it was recognized that at present there are no better options.

The current informal structure of the ERFP is considered as not sufficient and a weak point by some NCs. As the ERFP network has no legal status, in some situations it is difficult to engage in certain activities or to play certain roles (e.g. be a partner in EU projects or become the Reference Centre for AnGR of the EU). On the other hand, the Secretariat is hosted by an institution that has a legal status. A permanent ERFP Secretariat could strengthen the functioning of ERFP also from a legal point of view. The heavy workload and a wide scope of activities of the Secretariat was perceived as a weakness by some respondents (7).

When the respondents were invited to provide their views on future opportunities of the ERFP, eight of them mentioned three or more examples, while two NCs had no ideas to share. In total, 50 examples were provided.

A wide range of future opportunities were proposed, for many NCs they were related to implementation of the EU Animal breeding regulation (1012/2016); the ERFP being a recognized expert body on conservation and sustainable use of AnGR. Through this role, ERFP could enhance their influence in shaping relevant AnGR EU policies and result in the ERFP serving as an advisor to the EU on AnGR related matters (10 NCs).

A number of respondents indicated that enrichment of the work of the Secretariat can be achieved through strengthening networking in different areas (e.g. research, breeding and conservation), by communicating directly with breeders, and through collaboration and exchange of experiences with other regions and other genetic resources/agrobiodiversity networks (8 NCs).

Some NCs suggested that increased society concern about biodiversity and environmental issues, climate change and sustainability, as well as general efforts to mainstream biodiversity issues at the national level, could result in the enhanced roles of farm animal genetic diversity, and in particular of local breeds due to their adaptability, robustness and connection with extensive production systems. Also, market trends towards specialized, niche, high quality products could help to maintain a wide diversity of local breeds and provide opportunities for enhancement of work of the ERFP (6 NCs).

Opportunities were also seen in connection with achieving a legal status and a permanent Secretariat: this may enhance the commitment of countries to financially contribute to the ERFP and increase the possibility for funding from various EU sources (4 NCs).

There were also suggestions that new developments in DAD-IS/EFABIS will provide countries with new tools, reports and graphics to facilitate studies on the status of AnGR, and could support communication with stakeholders and the general public. The possibility of enhanced communication and collaboration with FAO would also contribute to this process ( $3 \mathrm{NCs})$.

Respondents provided 46 potential threats to the ERFP, with seven NCs identifying three or more threats. Three NCs were of the view that at the moment, there are 
no serious threats to the further development of the ERFP. Ten NCs considered insufficient financing as a potential threat to the ERFP which could result from a number of countries not providing their annual voluntary financial contributions. This would result in insufficient resources to support the Secretariat, will decrease yearly budget and activities. Some respondents saw lack of hosts for the ERFP Secretariat as a possible threat. Only a limited number of countries are capable of hosting a rotating Secretariat, and should country budgets decrease, this could result in no country being able or willing to voluntarily undertake the extra costs and efforts of hosting the ERFP Secretariat.

Other identified issues included insufficient outreach and visibility of the ERFP; and limited impacts and outputs, especially in regard to formal collaboration with the EU Commission and EU experts from Universities (6 NCs). Some expressed the view that other bodies, such as the Animal Task Force are overshadowing the influence of the ERFP in decision making and providing recommendations at the EC level.

Another possible identified threat is the lack of sufficient valorisation of AnGR, and their products, as well, lack of public recognition of the importance of AnGR remains a threat. Limited collaboration with relevant NGOs, research, industry and government networks was indicated as a threat by five respondents. NCs also mentioned different levels of interest in AnGR within countries, and their different priorities which result in inactive members within the network due to limitations in financial and human resources ( $7 \mathrm{NCs}$ ). The voluntary nature of the work within the ERFP might result in problems with motivating national experts to contribute to the work of ERFP.

The informal character of the ERFP platform was also perceived as a long-term threat (3). Other single comments referred to dependency on FAO to modify the EFABIS/DAD-IS database, which results in less freedom and independence for ERFP. One NC suggested that ERFP is prone to the same threats as animal production in general.

\section{Discussion}

It was surprising that there is little effort at the national level to ensure institutional memory while nominating a new NC. The majority of newly nominated NCs were not at all or only briefly prepared for this job, which is not helpful taking into account the dynamic evolution and the culture of the ERFP. Hoffmann and Scherf (2010) observed that Country Reports from Europe revealed the differences between the activities undertaken by NCs based in ministries and those based in universities or research institutes. The latter clearly focuses on research, whereas the group working in ministries worked more strategically for the country.

The survey showed a wide variety of situations in regard to participation of NCs and national experts in the different ERFP bodies. There are countries where the NC is the only and often extremely active member of the ERFP community, but cannot 
for various reasons enlist other national experts. This is usually due to a lack of human and financial resources. The other extreme situation is when the NC is a high profile member of their countries' administration, and delegates tasks to a staff, with little or no personal involvement in ERFP activities.

The survey indicated that the majority of NCs felt they benefited from involvement in the work of FAO. This collaboration provided an opportunity for better understanding of global AnGR management issues and allowed for NCs to contribute to strategy and programme developments at the global level, which in turn enhanced motivation for work at the national level.

The survey confirmed that one-third of NCs are involved in work at the EU level and in expert groups at the Commission and Council, which is highly beneficial for the ERFP community. This participation helps to increase awareness of new legislation (as it was in case of animal breeding and veterinary legislation), and allows NCs to contribute to new issues taken up at various EU fora. The important question is how to find ways to involve currently less active NCs in the work of ERFP throughout the year.

Diverse views were provided on the rotational hosting of the ERFP Secretariat. After discussion at the GA in 2018, a decision was taken to further investigate the pros and cons of various options, keeping in mind that change could require additional efforts and resources. This analysis should be concluded within two years.

Respondents indicated a diverse range of capacity building needs at the national level. More support was indicated from the ERFP in areas that require technical knowledge (e.g. cryo-conservation or valorisation of breed products and services), and access to a broad range of information on approaches (e.g. development of policies and legislation). These suggestions are in line with the analysis by Lauvie et al. (2014), who observed that economic added value of AnGR is of primary importance. Different types of development initiatives are underway to increase added value of rare or local breeds and more attention should be paid to these initiatives (Lauvie and Couix, 2012).

The need for enhancing networking among key stakeholders and end-users to explore marketing opportunities, such as quality assurance schemes and shortening supply chains was also recognized in the report of the Preparatory action on EU plant and animal genetic resources (European Commission, 2016). It was recommended that the EU develop an agro-biodiversity strategy that considers the conservation and valorisation of agricultural and forestry genetic resources in line with the EU Biodiversity Strategy. This strategy should encompass different domains and different Directorate Generals (DGs) of the European Commission.

The call for more collaboration with other genetic resources groups has been implemented through preparation of the Horizon 2020 CSA project GenRes Bridge (http://www.genresbridge.eu/).

The GenRes Bridge project started 1st January 2019. The main aim of the project is to strengthen the conservation and sustainable use of genetic resources by bringing together three leading networks in the European Genetic Resources domain: the European Cooperative Programme for Plant Genetic Resources (ECPGR), responsible 
for crops; the European Forest Genetic Resources Programme (EUFORGEN) for forests; and the ERFP for animals.

The GenRes Bridge will enable participants in these networks to share perspectives, exchange best practices, harmonise standards and collaborate on training and the use of resources. The most important expected outcome of the project is an integrated strategy for the management of Genetic Resources in Europe, which will support and contribute to the new EU Biodiversity Strategy. The ERFP network is represented by seven project partners.

The NCs recognized that in the early years of implementation of the Global Strategy (FAO, 1999), and since 2007, the Global Plan of Action for AnGR (FAO, 2007), the role of ERFP was critical in building recognition of the importance of the work of the NCs. Without the ERFP, building a strong national position of the NC would not be as successful. Most of NCs are of the view that their position is currently well established and recognized at the national level. However, there are still countries where the ERFP is not well known by governments, and therefore, the role and respect for the importance of the NC is limited.

The work of ERFP, especially in support of implementation of the Global Plan of Action for AnGR (FAO, 2007), contributes to enhanced understanding of the importance of management of AnGR, to information sharing on the developments at the European level and stimulates national authorities to further develop AnGR relevant policies.

The perception of certain activities/decisions undertaken by the ERFP has been dynamic and changed over time. With establishment of permanent WGs and other ERFP bodies in 2011, and presentation of reports on activities on these bodies during the GA, the obligatory annual national reports were not required any more. However, some NCs proposed that national reports (presenting highlights of activities) should be re-introduced and should be posted on the new ERFP website.

The SWOT analysis provided an excellent basis for further discussions that resulted in recommendations for future priorities of the ERFP, and preparation of the next MYPOW. The areas of activities adopted in the MYPOW 2019-2023 (ERFP, 2019), build on major suggestions expressed by the NCs in the survey. The first area was further improvement of the effectiveness of the ERFP structure. The main decision was to establish a TF to undertake a study to analyse the pros and cons of a permanent Secretariat versus a rotational one, and to explore opportunities for establishment of a permanent Secretariat of the ERFP. It was also decided to take special efforts, including involvement of SC Members, to initiate/intensify collaboration with countries that are currently less, or not active within the ERFP framework.

The second area of activity was networking and communication, including development of communication tools and collaboration with other European genetic resources networks, as well as the wider exchange of information about national activities.

The important part of MYPOW 2019-2023, as requested by NCs, is continuous support of the ERFP for international processes in the field of AnGR, including support for participation within FAO processes (ITWG-AnG and CGRFA), as well as other relevant international processes including the CBD and the Nagoya Protocol, and the EU. 
The MYPOW 2019-2023 covers important management activities aimed at improvement of documentation of AnGR and in situ conservation, and ex-situ conservation, within Europe, with special focus on EUGENA follow up and improvement of gene bank management (ERFP, 2019).

A key summary point of the SWOT analysis indicates that the current strengths of the ERFP structure is based on solidarity, open participation and collaboration of all countries in the region.

According to the European Commission (2016), the value of the European regional networks, including ERFP, lies in the fact that they focused on practical collaboration among stakeholders active in this field, while national governments tended to give political priority to the work of the FAO CGRFA.

Respondents noted that some countries are much more active than the others. As indicated by Hoffmann and Scherf (2010), "different countries are taking steps at different speeds and with different priorities" that fit their own priorities, conditions and capacities and available funding sources. Therefore, sharing experiences and learning from each other is crucial. This is especially true when national activities and regional collaboration are still in the early process of development, and information on already implemented supportive policies, efficient organizational infrastructure and institutions, options to ensure long-term financial support might be very useful to many countries within the network (Belew et al., 2016).

The analyses of second country reports by Leroy et al. (2016), clearly illustrated that the extent of implementation for most of the activities is positively correlated within and across countries, and a number of NCs are leaders at both the national and international levels.

It was pointed out by Leroy et al. (2017) that some activities, especially relevant to AnGR conservation, are dependent on public services, including financial incentives and extension assistance to support in situ conservation of endangered breeds and to improve AnGR management. As indicated by respondents, if such actions are not considered a priority at the national level, then the involvement of the NCs in ERFP activities is likely to be limited.

With milestone developments at the EU level (1012/2016 EU Regulation), new opportunities and potential new roles for the ERFP Secretariat were identified. Respondents indicated that this should provide for a review of the legal status of the ERFP as well as consideration of the current system of the rotational Secretariat. Diverse views on these potential developments were expressed in the survey.

While the NCs identified a number of potential future threats to the ERFP, they also concluded that no immediate threat was apparent. The key threats identified were: potential insufficient country contributions, lack of volunteers to host the rotational secretariat, and changing priorities of public policy on AnGR.

During preparation of the second State of the World Report on AnGR, four regional focal points (RFP) and networks provided their reports, namely: the ERFP; the Regional Focal Point for Latin America and the Caribbean; the Animal Genetic Resources Network - Southwest Pacific; and the Asian Animal Genetic Resources Network. As of mid-2014, one more regional body was operational, the Sub-Region- 
al Focal Point for West and Central Africa (FAO, 2015). Unfortunately, published information and analysis of regional activities and issues is limited. During FAO Global Workshops for NCs, there are usually presentations on current activities of regions, but these tend to be rather descriptive than analytical.

The main activity of the Regional Focal Point for Latin America and the Caribbean (established in 2007), has been the organization of regional workshops for NCs. Reported priorities for the future include: seeking financial support for training courses and collaborative activities at the regional and/or bilateral levels (FAO, 2015; Mariante, 2016). The main activities in the Southwest Pacific region are to: support an online network for NCs, facilitate discussions, disseminate information and enhance communication. A number of countries in the region are involved in characterization and conservation projects for locally adapted pigs and chickens.

A Sub-Regional Focal Point for West and Central Africa was established in 2012. The focal point reported a number of priorities for future action but did not take part in the 2014 round of reporting. The Asian Animal Genetic Resources Network was established in late 2013 (http://breeding.dld.go.th/biodiversity/RFP/Home.html). It has decided on its organizational structure, and agreed to focus on information exchange, providing assistance and technical advice, and to mobilize funds (FAO, 2015).

The EC Preparatory Action on GRFA concluded that at present, the formal networks at the European level, ECPGR, EUFORGEN, ERFP and MIRRI (Microbial Resource Research Infrastructure), do not have sufficient impact to effectively promote the conservation and sustainable use of GRFA (European Commission, 2016). The same sentiments were expressed by the NCs participating in the survey. Even though improvements have been observed since the establishment of the EU coordination platforms, including four networks, there is still a lot to be done, especially to enhance integration and exchange of knowledge and experiences among networks and between in situ and ex situ conservation activities (European Commission, 2016). The expectation of NCs is that implementation of the GenRes Bridge project should open new opportunities for enhancement of further work of the ERFP.

In summary, three strategic issues emerged from the survey. The first, supported by all NCs, is achieving full participation of all countries in the region in activities of the ERFP. The second is, examination of the potential benefits for a permanent ERFP Secretariat, as has already been achieved by the other related networks (ECPGR, EUFORGEN). The third is, enhancing the visibility of the network and its role in policy and legislation development.

\section{Acknowledgements}

The work was supported by the European Regional Focal Point for Animal Genetic Resources.

\section{References}

B e lew A.K., Te s fay e K., B el ay G., A s s e fa G. (2016). The State of Conservation of Animal Genetic Resources in Developing Countries: A Review. Int. J. Pharma Med. Biol. Sci., 5. 
ERFP (2019). Multi-year programme of work (MYPOW) for the period 2019-2023. https://www.animalgeneticresources.net/wp-content/uploads/2018/01/19-23-MyPow.pdf

ERFP (2020). European Regional Focal Point for Animal Genetic Resources website: https://www.animalgeneticresources.net/

European Commission (2016). Preparatory action on EU plant and animal genetic resources, Final Report, European Commission, Catalogue number KF-01-16-078-EN-N, doi: 10.2762/657280

FAO (1999). The Global Strategy for the Management of Farm Animal Genetic Resources: Executive Brief. Rome, Italy.

FAO (2007). Global Plan of Action for Animal Genetic Resources and the Interlaken Declaration, Rome, Italy FAO Commission on Genetic Resources for Food and Agriculture. http://www.fao.org/3/aa1404e.pdf

FAO (2015). The Second Report on the State of the World's Animal Genetic Resources for Food And Agriculture, edited by B.D. Scherf and D. Pilling. FAO Commission on Genetic Resources for Food and Agriculture Assessments, Rome. http://www.fao.org/ag/againfo/programmes/en/genetics/ Second_state.html

Hoffmann I., S cherf B. (2010). Implementing the global plan of action for animal genetic resources, animal genetic resources, 47: 1-10. (C) Food and Agriculture Organization of the United Nations, 2010, doi:10.1017/S2078633610001050

K u b b ing a B., H o ffm a n n I., S c h e rf B. (2007). Passing on the fire - to further inspire people to contribute to the management of animal genetic resources. AGRI, 41: 1-7.

L a u vi e A., C o u ix N. (2012). Diversité des formes de valorisation des populations animaleslocales et gestion des ressources génétiques animales (Different ways to valorise localbreeds and management of animal genetic resources). INRA Prod. Anim., 25: 431-440.

Lauvie A., Couix N., Verrier E. (2014). No Development, No Conservation: Elements from the Conservation of Farm Animal Genetic Resources. Society \& Natural Resources. An Int. J., 27: 1331-1338.

L er o y G., B e s bes B., B o e t t c her P., Hoffmann I., Pilling D., B a u mung R., S cherf B. (2016). Factors and determinants of animal genetic resources management activities across the world. Livest. Sci., 189: 70-77.

Leroy G., Baumung R., Notter D., Verrier E., Wurzinger M., Scherf B. (2017). Stakeholder involvement and the management of animal genetic resources across the world. Livest. Sci., 198: 120-128.

Mariante A.S. (2016). Conservation of animal genetic resources in Latin America and the Caribbean and present status of the Regional Focal Point. https:/www.slideshare.net/ExternalEvents/ conservation-of-animal-genetic-resources-in-latin-america-and-the-caribbean-and-present-statusof-the-regional-focal-point

Mart y n i u k E. (2018). Report of the ERFP Ad Hoc Action: ERFP SWOT General Assembly, Zagreb, 25-26.08.2018. https:/www.animalgeneticresources.net/wp-content/uploads/2018/01/12_ERFP_ Assembly_Zagreb_2018_SWOT_ElzbietaMartyniuk.pdf

Martyniuk E., Plān che e na $1 \bar{t}$ D. (1998). Animal genetic resources and sustainable utilisation in Europe. Proc. 6th World Congress on Genetics Applied to Livestock Production. Armidale, Australia, 28: 35-42.

Mäki-Tanila A., Hiemstra S.J. (2010). Regional issues on animal genetic resources: trends, policies and networking in Europe. Food and Agriculture Organization of the United Nations. Anim. Genet. Res., 47: 125-136.

Wa g n e r H-G.R., H a m m on d K. (1999). The management of farm animal genetic resources and FAO's Global Strategy. Deutscher Tropentag 1999 in Berlin.

Session: Biodiversity and Development of Animal Genetic Resources.

https://ttp.gwdg.de/pub/tropentag/proceedings/1999/referate/BDA1.pdf

Received: 11 V 2020

Accepted: 1 XII 2020 